\title{
Morphometric characteristics of the thoracolumbar and lumbar vertebrae in the Greek population: a computed tomography-based study on 900 vertebrae-“Hellenic Spine Society (HSS) 2017 Award Winner"
}

Theodoros B. Grivas ${ }^{1 *}$ (D), Olga Savvidou², Stefanos Binos ${ }^{1}$, Georgios Vynichakis ${ }^{1}$, Dimitrios Lykouris ${ }^{1}$, Michail Skaliotis ${ }^{1}$, Eleni Velissariou ${ }^{4}$, Konstandinos Giotopoulos ${ }^{3}$ and Konstandinos Velissarios ${ }^{3}$

\begin{abstract}
Background: Vertebrae morphology appears to have genetic and ethnic variations. Knowledge of the vertebra and pedicle morphology is essential for proper selection and safe application of transpedicular screws. The aim of this study is to create a morphometric database for thoracolumbar and lumbar vertebrae (T9-L5) among individuals of both sexes in the Greek population.

Material and methods: The morphometric dimensions of T9-L5 vertebrae on computed tomography (CT) scan images were measured in 100 adults (79 males and 21 females), without spinal pathology, age from 33 to 87 years old (mean $70 \pm 8.73$ years). The anterior vertebral body height (AVBH), the posterior vertebral body height (PVBH), the angle formed by the upper end plate of vertebral body and the horizontal line in the sagittal plane, the inner cancellous and outer cortical pedicle height and width, the angle formed by the longitudinal trajectory of the rightand left-sided pedicles and the midline anteroposterior axis of the vertebra (pedicle axis angle (PAA)), and the postero-anterior trajectory's length of the pedicle from the entry point to the anterior cortex of the vertebra (PTLP), for the right- and left-sided pedicles, were calculated. The Mann-Whitney $U$ tests were conducted to compare the differences in various morphometric characteristics between sexes. The collected data were statistically analyzed using the SAS/STAT software 3.1.3 and SPSS version 22. The statistical significance was set at the level of $p<0.05$. The intra- and inter-observer reliability of the measured parameters was also calculated.

(Continued on next page)
\end{abstract}

\footnotetext{
* Correspondence: tgri69@otenet.gr

'Orthopaedics and Traumatology Department, "Tzaneio" General Hospital of

Piraeus, Piraeus, Greece

Full list of author information is available at the end of the article
}

(c) The Author(s). 2019 Open Access This article is distributed under the terms of the Creative Commons Attribution 4.0 International License (http://creativecommons.org/licenses/by/4.0/), which permits unrestricted use, distribution, and reproduction in any medium, provided you give appropriate credit to the original author(s) and the source, provide a link to the Creative Commons license, and indicate if changes were made. The Creative Commons Public Domain Dedication waiver (http://creativecommons.org/publicdomain/zero/1.0/) applies to the data made available in this article, unless otherwise stated. 
(Continued from previous page)

Results: The L5 vertebra had the maximum AVBH with a mean of $28.47 \mathrm{~mm}$ (SD $\pm 2.55 \mathrm{~mm}$ ) in males and $26.48 \mathrm{~mm}$ (SD $\pm 1.61 \mathrm{~mm}$ ) in females. The maximum PVBH in males was at L1 vertebra with a mean of $27.77 \mathrm{~mm}(\mathrm{SD} \pm 1.64 \mathrm{~mm})$ and in females at $\mathrm{L} 2$ vertebral with a mean of $27.11 \mathrm{~mm}(\mathrm{SD} \pm 1.27 \mathrm{~mm}$ ). Regarding the left pedicle dimensions, the maximum inner cancellous and outer cortical pedicle height was at T11 with a mean of $12.86 \mathrm{~mm}$ (SD $\pm 1.26 \mathrm{~mm}$ ) and $18.82 \mathrm{~mm}$ (SD $\pm 1.37 \mathrm{~mm}$ ) in males and $10.24 \mathrm{~mm}$ (SD $\pm 1.88 \mathrm{~mm}$ ) and $16.19 \mathrm{~mm}$ (SD $\pm 3.27 \mathrm{~mm}$ ) in females, respectively. The maximum inner cancellous and outer cortical pedicle width was at L5 with a mean of $11.57 \mathrm{~mm}$ (SD $\pm 1.97 \mathrm{~mm}$ ) and $17.08 \mathrm{~mm}$ (SD $\pm 1.97 \mathrm{~mm}$ ) in males and $10.24 \mathrm{~mm}(\mathrm{SD} \pm 1.88 \mathrm{~mm})$ and $16.27 \mathrm{~mm}$ (SD $\pm 3.27 \mathrm{~mm})$ in females, respectively. The largest PAA was found at the L5 with a mean angle of $26.23^{\circ}\left(S D \pm 2.65^{\circ}\right)$ in males and $23.63^{\circ}\left(S D \pm 4.59^{\circ}\right)$ in females, respectively. The maximum PTLP was found at the level of $L 4$ with a mean of $55.31 \mathrm{~mm}$ (SD $\pm 4.52 \mathrm{~mm}$ ) in males and $48.7 \mathrm{~mm}$ (SD $\pm 4.17 \mathrm{~mm}$ ) in females, respectively. Regarding the right pedicle dimensions, the maximum inner cancellous and outer cortical pedicle height was found at T12 with a mean of $13.03 \mathrm{~mm}(\mathrm{SD} \pm 2.01 \mathrm{~mm})$ and $18.01 \mathrm{~mm}(\mathrm{SD} \pm 1.56 \mathrm{~mm})$ in males and $10.24 \mathrm{~mm}(\mathrm{SD} \pm 1.23$ $\mathrm{mm})$ and $16.14 \mathrm{~mm}(\mathrm{SD} \pm 1.23 \mathrm{~mm})$ in females, respectively. The maximum inner cancellous and outer cortical pedicle width was at $L 5$ with a mean of $11.3 \mathrm{~mm}$ (SD $\pm 2.86 \mathrm{~mm}$ ) and $16.34 \mathrm{~mm}$ (SD $\pm 2.98 \mathrm{~mm}$ ) in males and $12 \mathrm{~mm}(\mathrm{SD} \pm 3.18 \mathrm{~mm}$ ) and $15.69 \mathrm{~mm}(\mathrm{SD} \pm 2.59 \mathrm{~mm})$ in females, respectively. The greater PAA was at the L5 vertebral with a mean of $25.7^{\circ}\left(\mathrm{SD} \pm 5.19^{\circ}\right)$ in males and $25.56^{\circ}\left(\mathrm{SD} \pm 5.31^{\circ}\right)$ in females, respectively. The maximum PTLP was at the level of $\mathrm{L} 3$ with a mean of $54.86 \mathrm{~mm}(\mathrm{SD} \pm 3.18 \mathrm{~mm}$ ) in males and $49.01 \mathrm{~mm}$ (SD $\pm 2.97 \mathrm{~mm}$ ) in females, respectively. At all vertebrae, the only statistically significant difference $(p<0.0001)$ between the two sexes was the mean PTLP of the right and the left pedicle. The L5 vertebra was found to have the largest AVBH, PAA, and pedicle width in male and female populations.

Conclusions: This study provides a database of morphometric characteristics on thoracolumbar and lumbar vertebrae from T9 to L5 in the Greek population. This database may prove to be of great significance for forthcoming comparative studies. It can also serve as a basis in order to detect pathological changes in the spine and furthermore to plan operative interventions. It was found that the dimensions of thoracolumbar and lumbar vertebrae in the Greek population are sex-dependent. In the current study, vertebra and pedicle dimensions seem to have some similarities compared to other Western populations. However, in the thoracolumbar region, the pedicles of T9 and T10 may hardly accommodate a 4.00-mm pedicle screw given the narrow inner cancellous pedicle width. Importantly, the vertebra and pedicle dimensions measured in the current study can be used to guide the selection of transpedicular screws in the Greek population and to guide further research.

Keywords: Morphometric characteristics, Thoracolumbar vertebrae, Lumbar vertebrae, Greek population, A computed tomography-based study

\section{Introduction}

Transpedicular screws are commonly used for posterior fixation in spinal fractures, deformity, instability, and degenerative disease [1-4]. However, their insertion is demanding, with the reported malpositioning rate up to $11 \%$, based on postoperative CT assessment $[5,6]$ and the overall incidence of neurological, visceral, and vascular complications up to $42 \%[2,7]$. Genetic and ethnic variations in width, height, and orientation of vertebra and pedicle dimensions have been documented [1, 2, 4, 5]. The morphometric analysis of the vertebrae and pedicles is a clinical necessity for the safe application of transpedicular screws in posterior spine instrumentation [8]. Furthermore, spine surgeons, in order to avoid serious intraoperative complications, have to assess carefully the morphometry of the vertebrae/pedicles preoperatively for patients undergoing transpedicular spine fixation. The aim of this study was to create a morphometric characteristic computed tomography (CT)-based database of thoracolumbar and lumbar (T9-L5) vertebrae for both sexes in the Greek population and to compare these findings with the analogous reported values in the available literature. Those individuals were picked from a pool of patients suffering vascular problems (mainly aortic aneurysmal disease) and had CT-angiography (mainly for abdominal aortic issues). We choose the T9 through L5 vertebrae in order to achieve homogeneity of the sample (visual vertebrae in all patients), since most of the CT scans did not involve the mid and upper thoracic vertebrae. To the authors' knowledge, there is only one study in the literature regarding the pedicles' dimensions in the Greek population [9].

\section{Material and methods}

After obtaining the hospital's IRB approval for this research study, a CT-based morphometric study from 


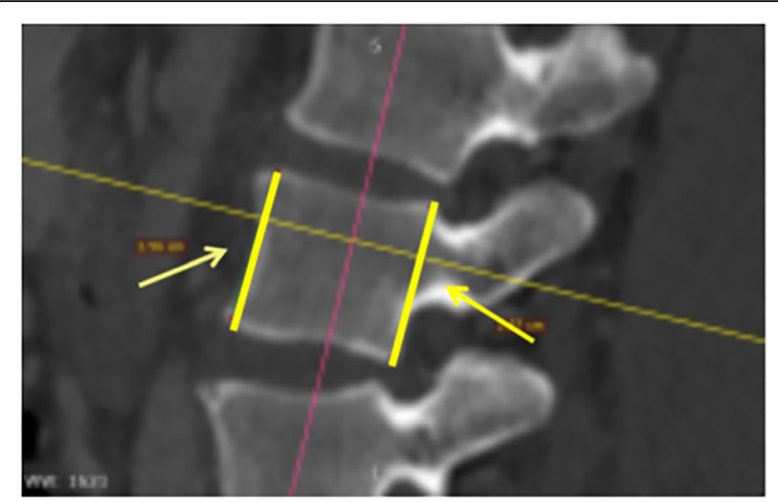

Fig. 1 The anterior vertebral body height (AVBH) and posterior vertebral body height (PVBH)

the ninth thoracic vertebra (T9) to the fifth lumbar vertebra (L5) for both sexes in the Greek population was carried out.

\section{The population studied}

The CT scan images from T9 to L5 vertebrae were studied in 100 adults, age from 33 to 87 years old (mean 70 \pm 8.73 years). There were 79 males and 21 females who were scheduled for vascular operations. Participants with a history of spinal surgery, vertebrae fractures, deformities, osteoporosis, and pre-existing spinal pathology

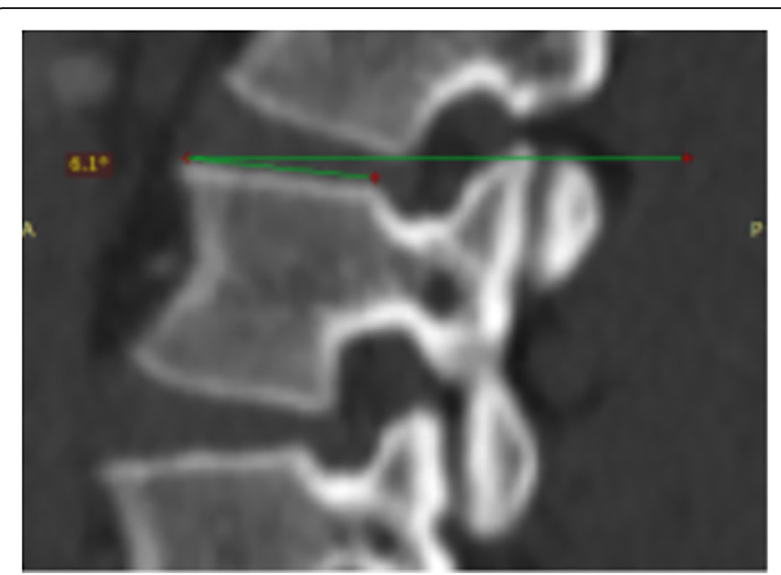

Fig. 2 The angle formed by the upper end plate of vertebral body with the horizontal line in the sagittal plane

were excluded from the study. Several dimensions of the vertebral bodies and the pedicles were measured.

\section{The measurements}

The anterior vertebral body height $(\mathrm{AVBH})$, the posterior vertebral body height (PVBH), (Fig. 1), the angle of the upper end plate of vertebral body with the horizontal line in the sagittal plane (Fig. 2), the inner cancellous and outer cortical pedicle height and width (Fig. 3), the angle formed by the longitudinal trajectory of the rightand left-sided pedicles and the midline anteroposterior

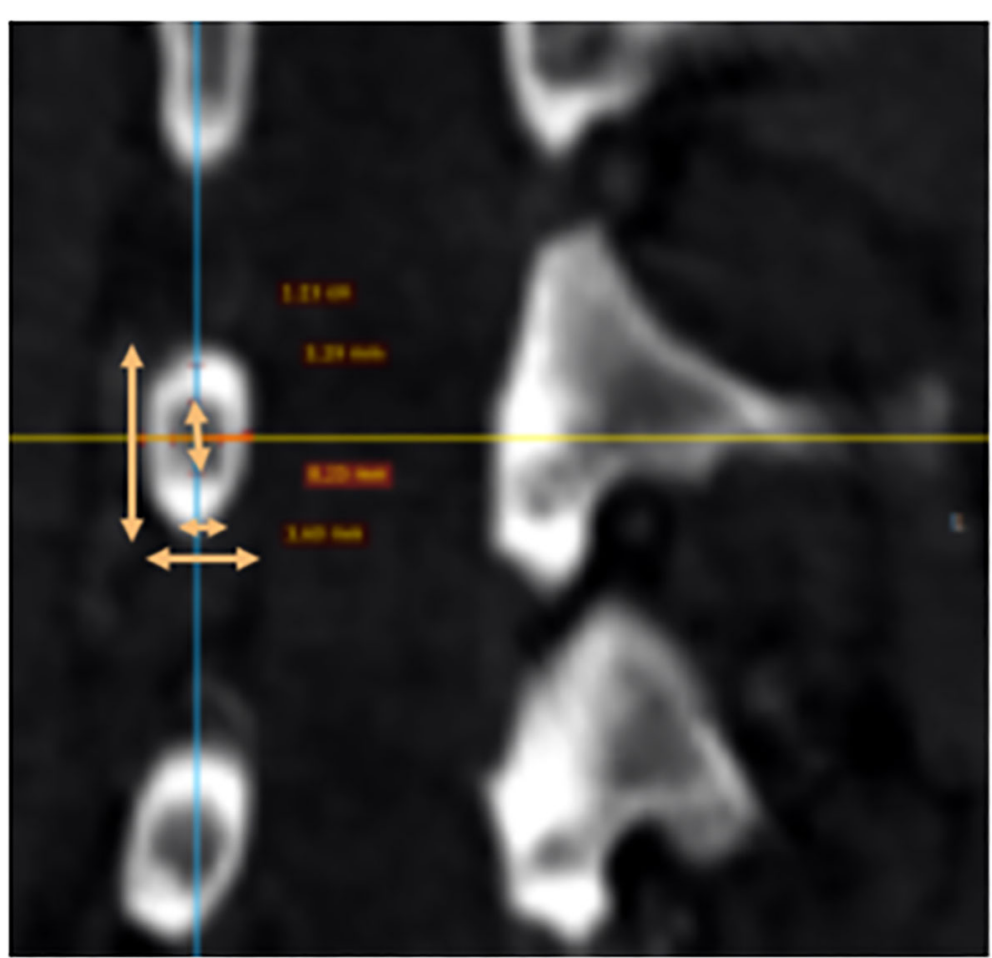

Fig. 3 The inner cancellous and outer cortical pedicle height and width 


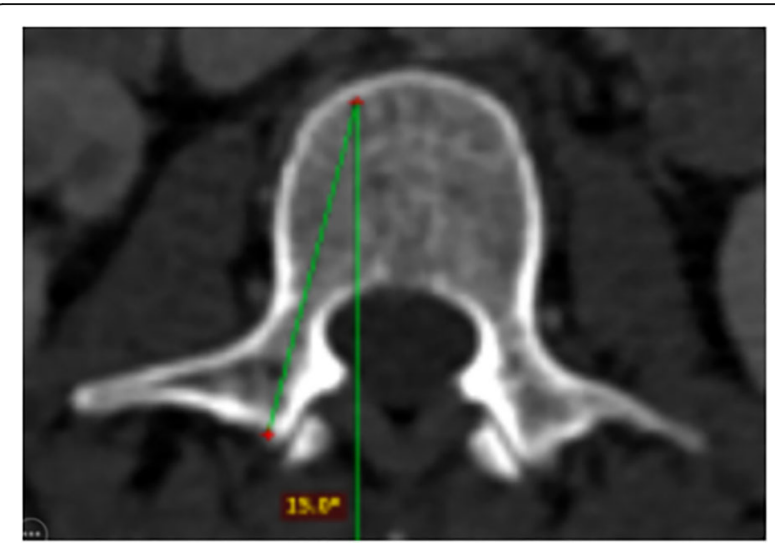

Fig. 4 The angle formed by the longitudinal trajectory of the rightand left-sided pedicles, and the midline anteroposterior axis of the vertebra (PAA)

axis of the vertebra (pedicle axis angle (PAA)) (Fig. 4), and the postero-anterior trajectory's length of the pedicle from the hypothetical entry point of the screw to the anterior cortex of the vertebra (PTLP) for the right- and left-sided pedicles (Fig. 5) for each sex were calculated.

\section{Statistical analysis}

The collected data were statistically analyzed using the SAS/STAT software 3.1 .3 and SPSS version 22. The non-parametric statistical technique of Mann-Whitney $U$ test was used to compare the same parameters in males

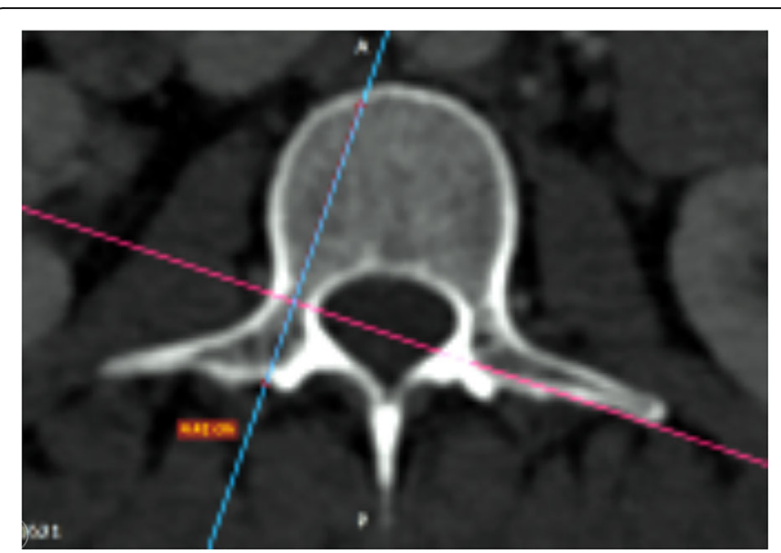

Fig. 5 The postero-anterior trajectory's length of the pedicle from the entry point of a hypothetical screw to the anterior cortex of the vertebra (PTLP) for the right- and left-sided pedicles

and females. Standard deviations (SD) and $p$ values of all vertebral level were calculated separately. The statistical significance was set at the level of $p<0.05$. The reliability study was also implemented.

\section{Results}

The maximum AVBH for both sexes was found at the L5 vertebra with a mean of $28.47 \mathrm{~mm}(\mathrm{SD} \pm 2.55 \mathrm{~mm}$ ) for males and $26.48 \mathrm{~mm}(\mathrm{SD} \pm 1.61 \mathrm{~mm})$ for females, respectively. The maximum PVBH in males was at L1 vertebra with a mean of $27.77 \mathrm{~mm}(\mathrm{SD} \pm 1.64 \mathrm{~mm})$, while in

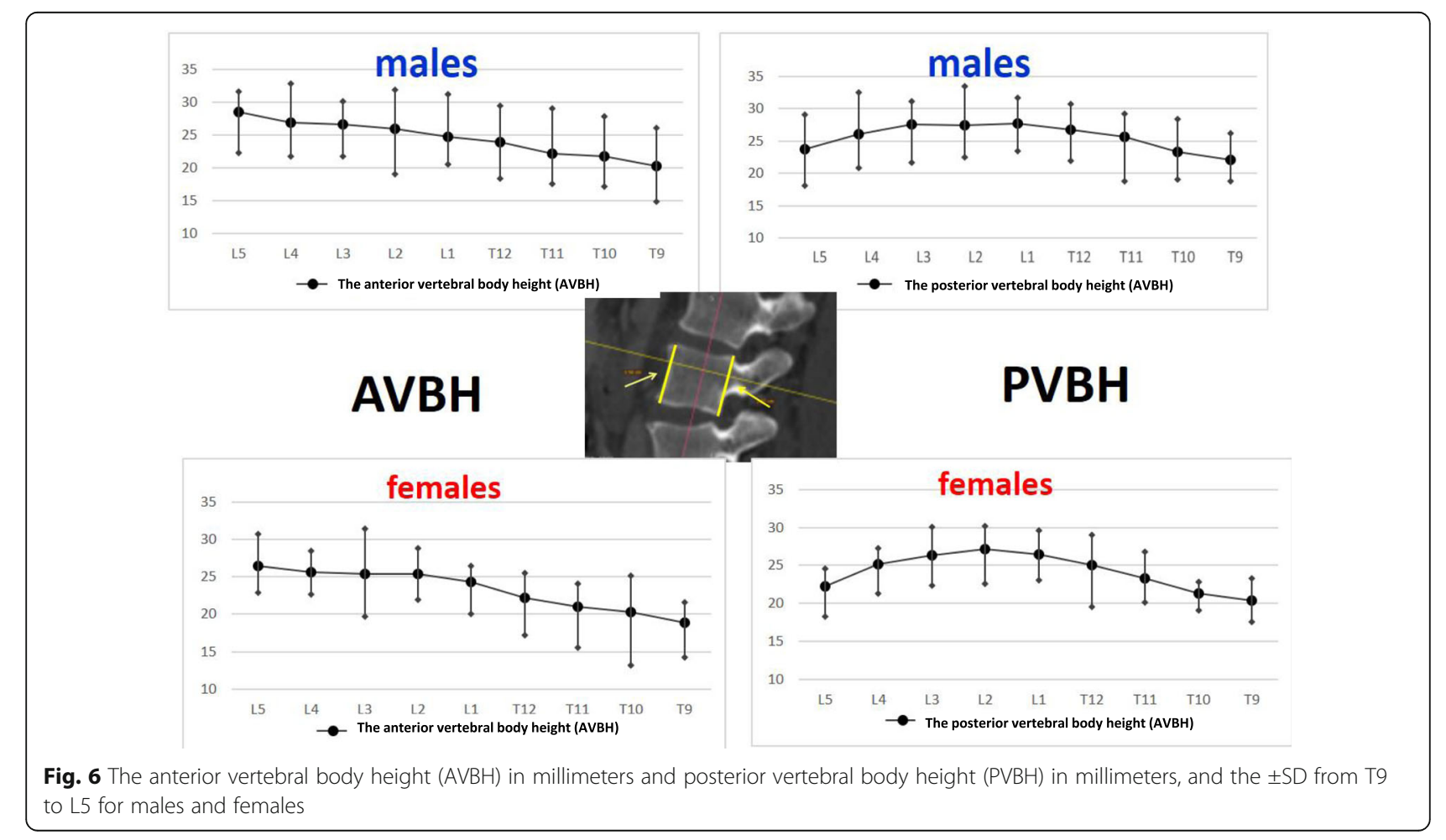


females at L2 vertebra with a mean of $27.11 \mathrm{~mm}(\mathrm{SD} \pm$ $1.27 \mathrm{~mm}$ ). The minimum AVBH and PVBH, for both sexes, were at T9 with a mean of $20.29 \mathrm{~mm}$ (SD \pm 1.79 $\mathrm{mm})$ and $22.14 \mathrm{~mm}(\mathrm{SD} \pm 1.38 \mathrm{~mm}$ ) for males and 18.83 $\mathrm{mm}(\mathrm{SD} \pm 1.36 \mathrm{~mm})$ and $20.37 \mathrm{~mm}(\mathrm{SD} \pm 0.98 \mathrm{~mm})$ for females, respectively. The mean AVBH increased gradually from T9 to L5, while the mean PVBH gradually increased from $\mathrm{T} 9$ to the L1 in males and L2 in females and then it decreased to the L5. The widest angle formed by the end plate of the vertebral body with the horizontal line in the sagittal plane, for males and females, was at L1 vertebra with a mean of $7.6^{\circ}\left(\mathrm{SD} \pm 2.18^{\circ}\right)$ in males and $9.5^{\circ}$ $\left(\mathrm{SD} \pm 6.56^{\circ}\right)$ in females, respectively. The narrowest angle for males and females was found at L5 vertebra with a mean of $-15.79^{\circ}\left(\mathrm{SD} \pm 478^{\circ}\right)$ for males and $-16.32^{\circ}$ (SD $\left.\pm 9.66^{\circ}\right)$ for females. The angle of the end plate of the vertebral body with the horizontal line in the sagittal plane increased from $\mathrm{T} 9$ to L1 vertebra and from L1 it decreased to L5 vertebra, with a negative angle meaning that the vertebra angled caudally.

Regarding the left pedicle, the largest pedicle height, for both sexes, was found at T11 with a mean inner cancellous height $12.86 \mathrm{~mm}$ (SD $\pm 1.26 \mathrm{~mm}$ ) and the widest outer cortical $18.82 \mathrm{~mm}$ (SD $\pm 1.37 \mathrm{~mm}$ ) for males and $10.24 \mathrm{~mm}$ (SD $\pm 1.88 \mathrm{~mm}$ ) and $16.19 \mathrm{~mm}$ (SD $\pm 2.1 \mathrm{~mm}$ ) for females. The smallest pedicle height for males was found at L5 with the inner cancellous and outer cortical height $7.24 \mathrm{~mm}(\mathrm{SD} \pm 1.39 \mathrm{~mm})$ and 11.96 $\mathrm{mm}(\mathrm{SD} \pm 1.8 \mathrm{~mm})$, respectively. For females, the smallest pedicle height was at T9, with a mean of $7.59 \mathrm{~mm}$ (SD $\pm 0.83 \mathrm{~mm})$ and $12.39 \mathrm{~mm}(\mathrm{SD} \pm 0.82 \mathrm{~mm})$ for the inner cancellous and outer cortical height, respectively. The mean pedicle height increased gradually from $\mathrm{T} 9$ to T11 and from T11 it decreased to L5. The widest pedicle width, for both sexes was at L5 vertebra with the mean inner cancellous and outer cortical width $11.57 \mathrm{~mm}$ (SD $\pm 1.97 \mathrm{~mm}$ ) and $17.08 \mathrm{~mm}(\mathrm{SD} \pm 1.97 \mathrm{~mm}$ ) for males and $12.7 \mathrm{~mm}(\mathrm{SD} \pm 4.25 \mathrm{~mm})$ and $16.27 \mathrm{~mm}(\mathrm{SD} \pm 3.27 \mathrm{~mm})$ for females, respectively. The narrowest pedicle width for males and females was found at T9 with a mean of $3.09 \mathrm{~mm}(\mathrm{SD} \pm 1.06 \mathrm{~mm}$ ) for inner cancellous and 6.11 $\mathrm{mm}$ (SD $\pm 1.47 \mathrm{~mm}$ ) for outer cortical for males, and $3.35 \mathrm{~mm}(\mathrm{SD} \pm 0.99 \mathrm{~mm})$ and $6.8 \mathrm{~mm}(\mathrm{SD} \pm 1.35 \mathrm{~mm})$ for female participants, respectively. The mean width of

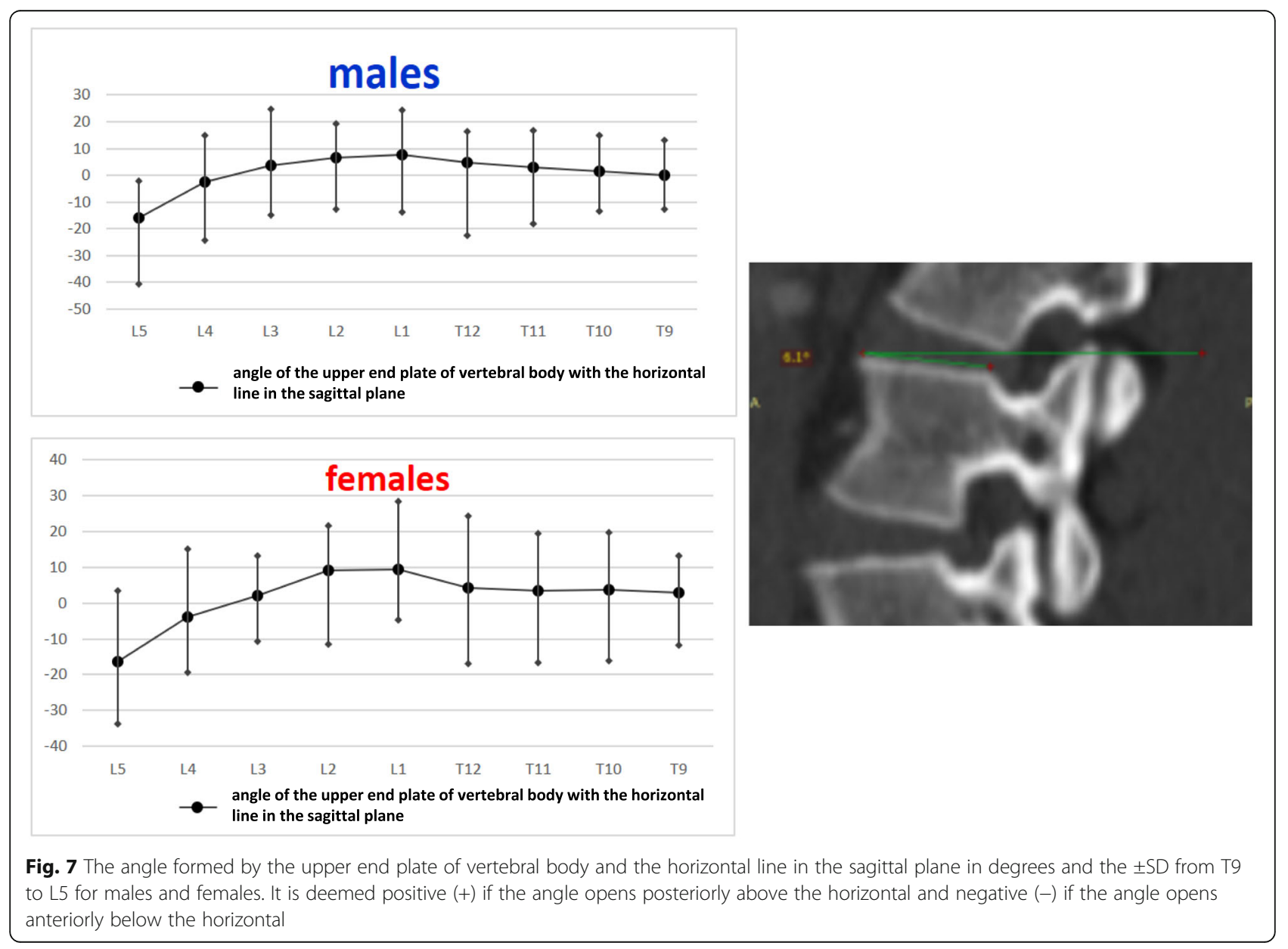


the left pedicle increased from T9 to L5 vertebra, with the narrowest inner cancellous at $\mathrm{T} 9$ and $\mathrm{T} 10$ vertebrae. The widest PAA was found at the L5 vertebra with a mean angle of $26.23^{\circ}$ (SD $\pm 2.65^{\circ}$ ) for males and $23.63^{\circ}\left(\mathrm{SD} \pm 4.59^{\circ}\right)$ for females. The narrowest mean PAA in males was at T12 vertebra with a mean of $9.4^{\circ}$ $\left(\mathrm{SD} \pm 3.86^{\circ}\right)$, while in females was at $\mathrm{T} 9$ with a mean of $9^{\circ}\left(\mathrm{SD} \pm 3.67^{\circ}\right)$. The mean PAA increased from thoracic vertebrae to L5. The longest PTLP was at the level of L4 with a mean of $55.31 \mathrm{~mm}$ (SD $\pm 4.52 \mathrm{~mm}$ ) for males and $48.7 \mathrm{~mm}(\mathrm{SD} \pm 4.17 \mathrm{~mm})$ for females. The shortest PTLP in males was at T9 with a mean of $47.2 \mathrm{~mm}(\mathrm{SD} \pm 3.18$ $\mathrm{mm}$ ) and in females at T12 with a mean of $40.95 \mathrm{~mm}$ (SD $\pm 3.79 \mathrm{~mm}$ ). The mean PTLP increased from the thoracic vertebrae to $\mathrm{L} 5$, with the shortest at $\mathrm{T} 9$ vertebra.

Regarding the right pedicle, the longest height was at T12 with the mean inner cancellous and outer cortical height of $13.03 \mathrm{~mm}$ (SD $\pm 2.01 \mathrm{~mm}$ ) and $18.01 \mathrm{~mm}$ (SD $\pm 1.56 \mathrm{~mm}$ ) for males and $10.24 \mathrm{~mm}(\mathrm{SD} \pm 1.23 \mathrm{~mm})$ and $16.14 \mathrm{~mm}(\mathrm{SD} \pm 1.37 \mathrm{~mm}$ ) for females. The shortest pedicle height was found at L5 vertebra, with the mean inner cancellous of $6.61 \mathrm{~mm}$ (SD $\pm 1.16 \mathrm{~mm}$ ) and the outer cortical of $11,68 \mathrm{~mm}$ (SD $\pm 0.92 \mathrm{~mm}$ ) in males and $7.76 \mathrm{~mm}(\mathrm{SD} \pm 1.19 \mathrm{~mm})$ and $12.59 \mathrm{~mm}(\mathrm{SD} \pm 2.5$ $\mathrm{mm}$ ) in females, respectively. The mean height of the right pedicle increased from $\mathrm{T} 9$ to $\mathrm{T} 12$ and from L1 decreased to L5. The widest pedicle width was found at L5, with the mean inner cancellous and outer cortical width of $11.3 \mathrm{~mm}$ (SD $\pm 2.86 \mathrm{~mm}$ ) and $16.34 \mathrm{~mm}$ (SD \pm 2.98 $\mathrm{mm}$ ) for males and $12 \mathrm{~mm}(\mathrm{SD} \pm 3.18 \mathrm{~mm}$ ) and 15.69 $\mathrm{mm}(\mathrm{SD} \pm 2.59 \mathrm{~mm})$ for females, respectively. The narrowest pedicle width was at T9 with a mean of $2.83 \mathrm{~mm}$ $(\mathrm{SD} \pm 0.97 \mathrm{~mm})$ and $5.68 \mathrm{~mm}(\mathrm{SD} \pm 1.35 \mathrm{~mm})$ for inner and outer width for males and $3.2 \mathrm{~mm}(\mathrm{SD} \pm 0.97 \mathrm{~mm})$ and $6.4 \mathrm{~mm}(\mathrm{SD} \pm 1.42 \mathrm{~mm})$ for females. The mean width of the right pedicle increased from T9 to T12 regarding the thoracic vertebrae and from L1 to L5 regarding the lumbar vertebrae, with the narrowest inner cancellous width at $\mathrm{T} 9$ and $\mathrm{T} 10$. The greatest PAA was at L5 with a mean of $25.7^{\circ}\left(\mathrm{SD} \pm 5.19^{\circ}\right)$ in males and $25.56^{\circ}\left(\mathrm{SD} \pm 5.31^{\circ}\right)$ in females. The smallest PAA in males was found at the level of T9 with a mean of $9.51^{\circ}$ $\left(\mathrm{SD} \pm 1.74^{\circ}\right)$; however, in females the $\mathrm{T} 10$ vertebra had the smallest mean PAA with a mean of $8.86^{\circ}$ (SD \pm $\left.8.13^{\circ}\right)$. The longest PTLP was at the level of L3 with a mean of $54.86 \mathrm{~mm}$ (SD $\pm 3.18 \mathrm{~mm}$ ) for males and 49.01 $\mathrm{mm}(\mathrm{SD} \pm 2.97 \mathrm{~mm})$ for females. The shortest PTLP was at T9 with a mean of $48.68 \mathrm{~mm}(\mathrm{SD} \pm 3.58 \mathrm{~mm}$ ) for males and 39.44 (SD $\pm 3 \mathrm{~mm})$ for females. The mean PTLP of the right pedicle increased from T9 to L4 in

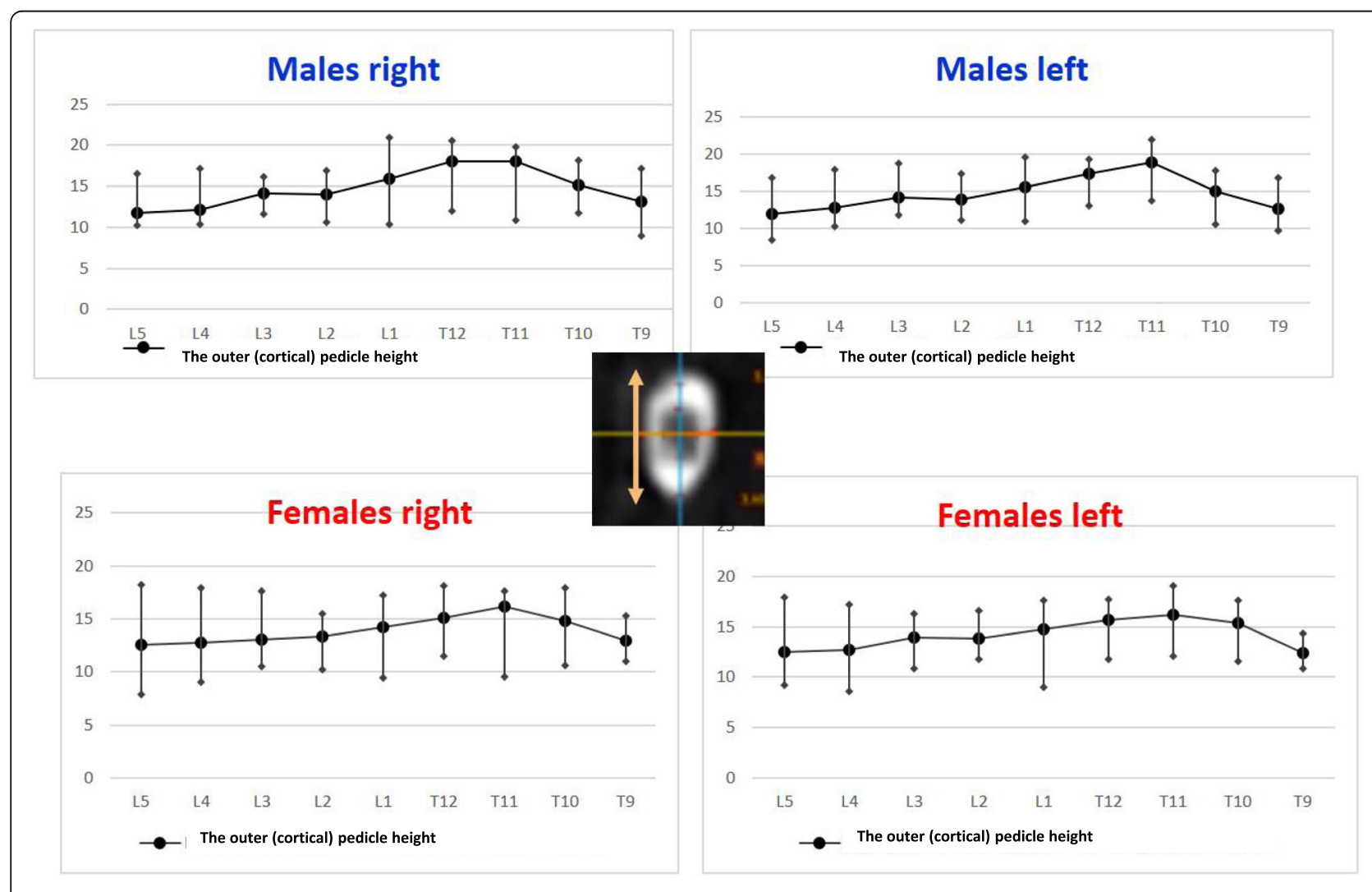

Fig. 8 The outer cortical right and left pedicle height and the $\pm S D$ in millimeters from $T 9$ to $L 5$ for males and females 
males and from T9 to L3 in females, with the shortest at $\mathrm{T} 9$ vertebra.

Regarding the statistical difference between sexes for each level of the thoracolumbar and lumbar spine from T9 to L5, it was found that in all vertebrae, a statistically significant difference $(p<0.0001)$ was observed for the PLTP of the left- and right-sided pedicles. Furthermore, at the L5 level, a statistically significant difference was observed for PVBH $(p<0.0091)$ and inner cancellous height of the left pedicle $(p<0.0193)$. At L4 level for inner cancellous and outer cortical width of both pedicles (left pedicle $p<0.0028$ and $p<0.0047$, and right pedicle $p<0.0042$ and 0.014 , respectively). At L3 level statistically significant difference was observed for PVBH $(p<0.0462)$ for inner and outer height and width of left pedicle, $(p<0.0002, p<0.0193, p<0.0039, p<0.0022$, respectively) and also inner and outer height of the right pedicle $(p<0.0045, p<0.0003)$ and only at the inner width $(p<0.025)$ but not at the outer one. At L2 level for the angle of the upper end plate of vertebral body with horizontal line in the sagittal plane $(p<0.0038)$, for the inner height $(p<0.0048)$, and the inner and outer width of the left pedicle $(p<0.0006$ and $p<0.0497)$, respectively.
The right pedicle at L1, there was a statistically significant difference in all the parameters except the angle of the upper end plate of vertebral body with horizontal line in sagittal plane, the left outer height and width, the right outer height, and the right PAA. At T12 level, a statistically significant difference $(p<0.0001)$ was observed for left and right pedicle inner height. At T11 level for left and right pedicle inner height and for the PVBH. At T10 level, a statistically significant difference $(p<0.0001)$ was observed for PVBH. As for the T9 level, the difference $(p<0.0001)$ was for the PVBH. The results are also presented in Figs. 6, 7, 8, 9, 10, 11, 12, and 13.

\section{The reliability study}

In the CTs, the slice thickness was ranging from 5 $\mathrm{mm}$ to $0.5 \mathrm{~mm}$. For the intra-class, correlation coefficient with $95 \%$ confidence interval was 0.998 for the length measurements, and the intra-class correlation coefficient with $95 \%$ confidence interval was 0.971 for the angular measurements. The reliability results were better when the slice thickness was smaller. The two-way mixed model for ICC was used (using the IBM SPSS version 22).

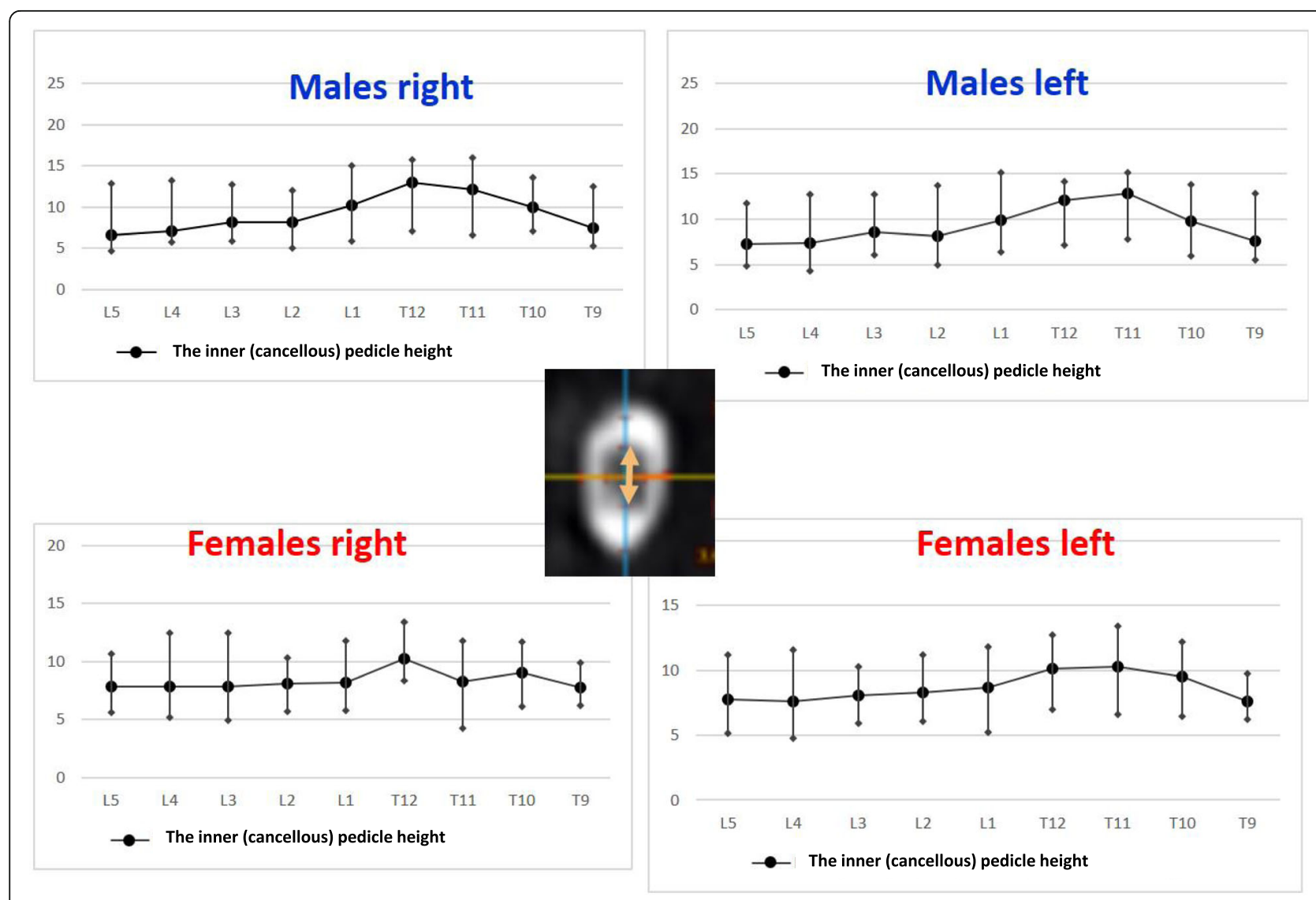

Fig. 9 The inner cancellous right and left pedicle height and the $\pm S D$ in millimeters from T9 to $L 5$ for males and females 


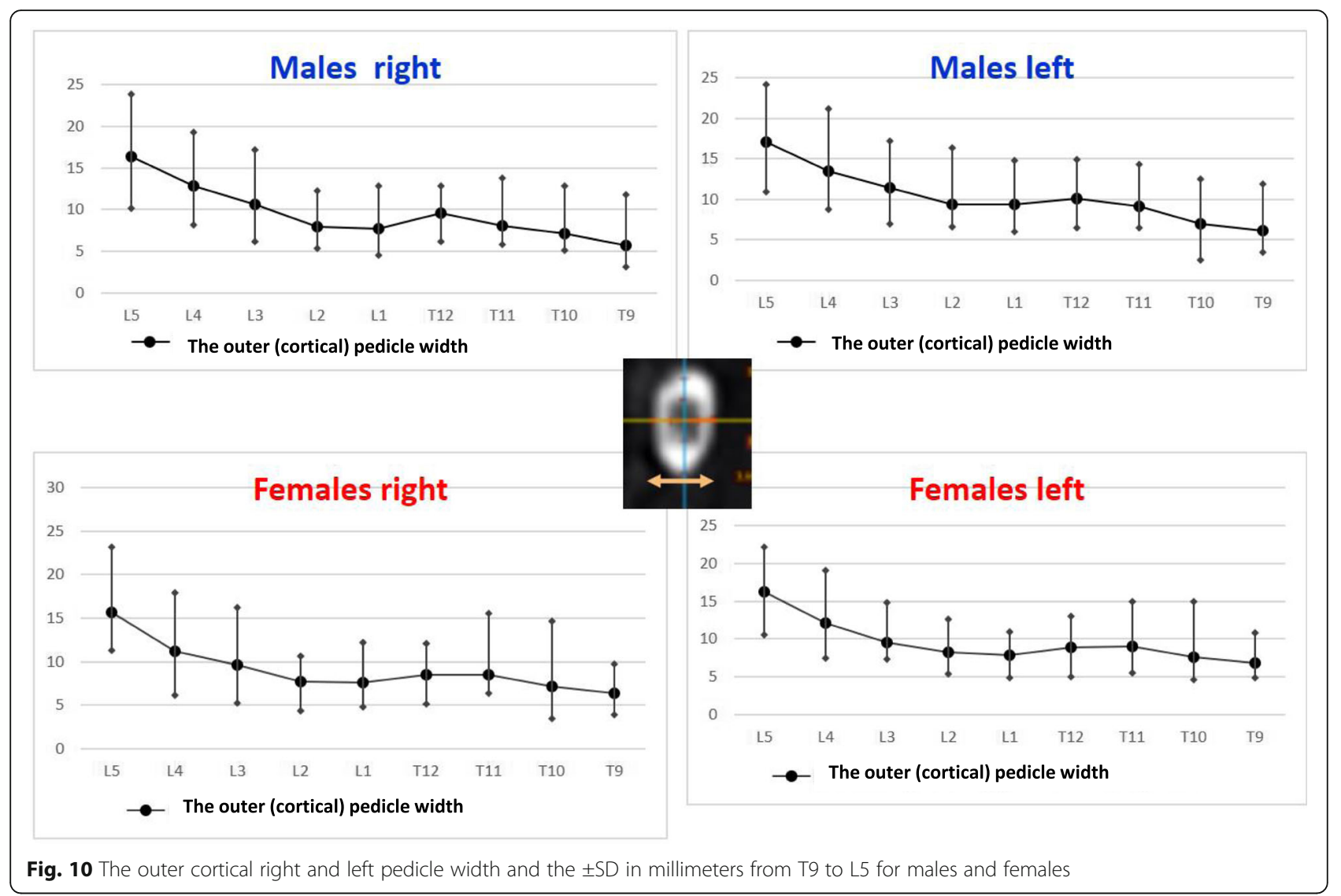

\section{Discussion}

The pedicle screws are used for the posterior spine fixation to treat various spine disorders or trauma. However, inaccurate placement is relatively common even when placement is performed under fluoroscopic control [5], and it can cause severe vascular and neurological complications [10]. However, in clinical practice, for safe and accurate screw placement, the screw dimensions as well as the proper position of the screw are essential. Optimum diameter of the pedicle screw is necessary to maximize the rigidity of the construct, as larger diameter screws may break the pedicle, while screws with narrower diameter do not offer sufficient resistance to pull out [11]. Regarding the screw length, short screws reduce the rigidity of the construct, while long screws may penetrate the anterior wall of the vertebral body and injure vital structures. Biomechanical studies have shown that the pull-out strength of a pedicle screw at $85 \%$ insertion depth is similar to the pullout strength at $100 \%$ insertion depth [12]. Another important parameter for proper screw position is the knowledge of PAA for each vertebra, in order to prevent medial or lateral pedicle wall breach [13]. Therefore, a profound knowledge of the morphometric characteristics of the vertebrae is needed [14].
Some morphometric measurements of the vertebrae and pedicles significantly differ among different ethnic groups and preoperative software-based morphometric data should be collected for preoperative planning [9, 15-19]. Vertebral morphometric measurements of the Greek population shared some similarities and differences with other ethnic groups. There is only one study in the literature regarding the pedicle dimensions in the Greek population. Christodoulou et al. [9] studied 12 human cadaveric spines (5 women and 7 men) with a mean age of 69.6 years (range 62 to 84 years) at the time of death. The authors measured the transverse and sagittal outside pedicle isthmus widths, the internal transverse diameter, and cortex width of pedicles with electronic calipers. In our study, the widest outer cortical pedicle width was at L5 with a mean of $17.08 \mathrm{~mm}$ (SD $\pm 1.97 \mathrm{~mm}$ ) at left pedicle in males. This is in accordance with the results of Christodoulou et al. [9] who found that the widest transverse diameter was at the same level of L5 with a mean of $11.3 \mathrm{~mm}$ (range 7.55-15.46 mm). Zindrick et al. [20], who conducted one of the largest morphometric measurements of the pedicles by CT in Western populations, found the same level with a mean of 


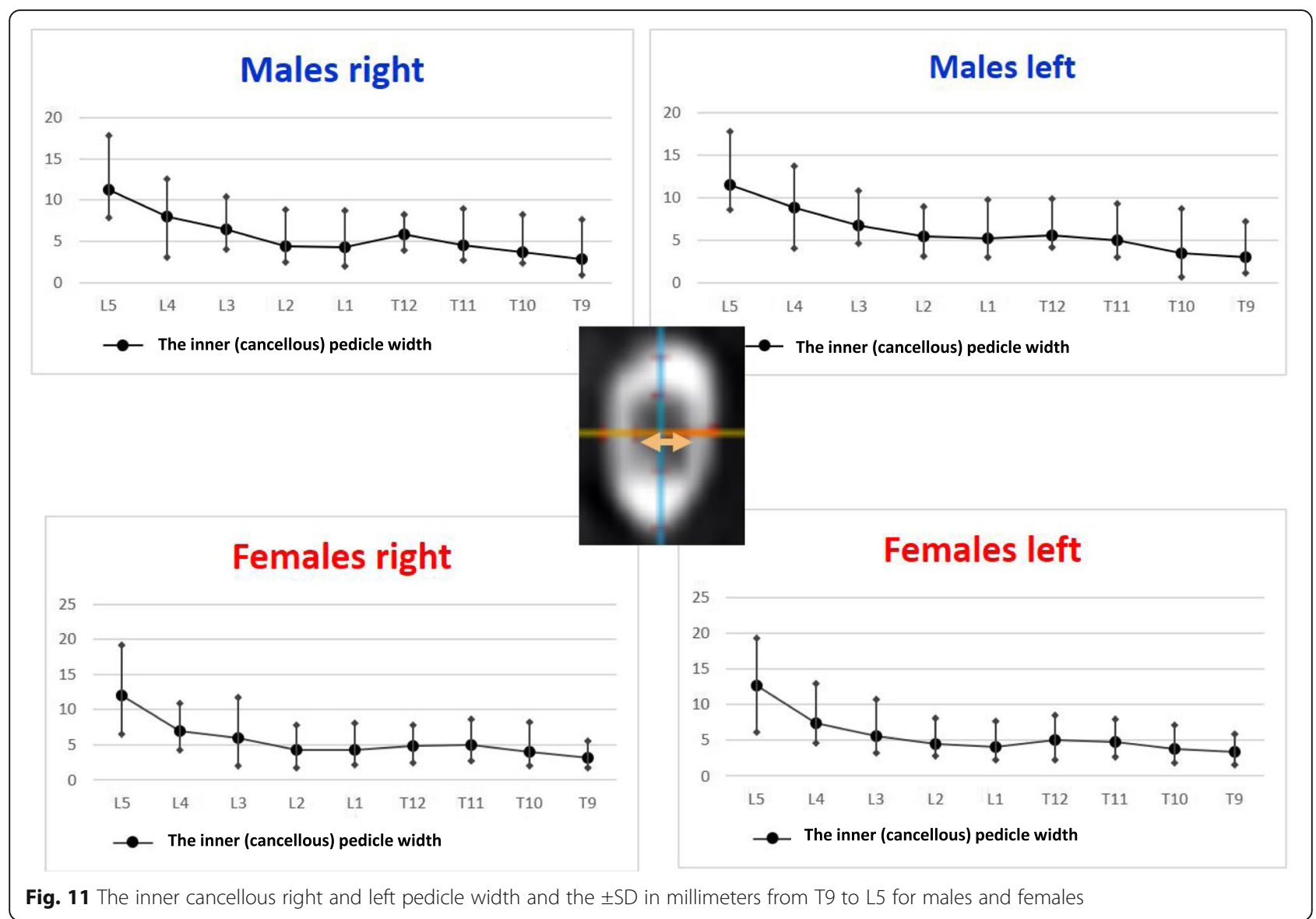

$18.0 \mathrm{~mm}$ (range $9.1-29.0 \mathrm{~mm}$ ), similar to our measurements. Regarding the widest inner cancellous pedicle width, in this study, it was at the L5 vertebra with a mean of $11.3 \mathrm{~mm}(\mathrm{SD} \pm 2.68 \mathrm{~mm})$ at the right pedicle in males. However, Christodoulou et al. [9] found the widest inner at L4 level with a mean of $8.26 \mathrm{~mm}$ (range $7.10-9.23 \mathrm{~mm}$ ). In this report, as far as the largest outer pedicle height is concern, it was found at T11 left pedicle in males with a mean of 18.82 ( $\mathrm{SD} \pm 1.37 \mathrm{~mm}$ ). This finding is also in accordance with the results of Christodoulou et al. [9] who found the largest height at the same level with a mean of $17.23 \mathrm{~mm}$ (range 14.84-19.57 $\mathrm{mm}$ ) and also with the results of Zindrick et al. [20] with a mean value of $17.4 \mathrm{~mm}$ (range 12.5-24.1 mm). The narrowest inner pedicle width was observed at T9 and T10 vertebrae in our study, with a mean from $2.83 \mathrm{~mm}$ $(\mathrm{SD} \pm 0.97 \mathrm{~mm})$ to $4.00 \mathrm{~mm}(\mathrm{SD} \pm 1.43 \mathrm{~mm})$ for male and female population, respectively. However, Christodoulou et al. [9] stated that a 5-mm-diameter screw may safely be inserted at the levels of T9 vertebra. Zindrick et al. [20] also found that the mean inner pedicle width at T9 and T10 was larger with
$6.1 \mathrm{~mm}$ (range $3.7-9.0 \mathrm{~mm}$ ) at T9 and $6.3 \mathrm{~mm}$ (range $3.1-8.5 \mathrm{~mm}$ ) at T10 vertebra. In clinical practice, the diameter of pedicle screws for thoracolumbar levels range from $4 \mathrm{~mm}$ to $7 \mathrm{~mm}$, with $1.0 \mathrm{~mm}$ clearance. [12]. Based on the analysis of the present study, in the Greek population, the pedicles of T9 and T10 vertebrae may hardly accommodate a $4.0-\mathrm{mm}$ pedicle screw, due to the narrow inner cancellous pedicle width. Studies have shown that pedicles between T4 and T8 should be measured on CT scans before an operation, because they might not be suitable for fixation with screw due to their narrow width $[14,16]$. Based on the results of this study, T9 and T10 must also be included in the CT scan preoperative, especially for the Greek population. Regarding the PAA of the pedicles in this study, the largest PAA was at L5 with a mean of $26.23^{\circ}\left(\mathrm{SD} \pm 2.65^{\circ}\right)$, at the left pedicle in males, while the smallest was found at $\mathrm{T} 9$ with a mean of $9^{\circ}\left(\mathrm{SD} \pm 3.67^{\circ}\right)$, at the left pedicle in females. Zindrick et al. [20] also stated that the largest angle was seen at L5 with the mean pedicle of $29.8^{\circ}$ (range $19.0-44.0^{\circ}$ ); however, the shallowest was at $\mathrm{T} 1$, with the mean PAA at T9 vertebra $7.6^{\circ}$ (range 


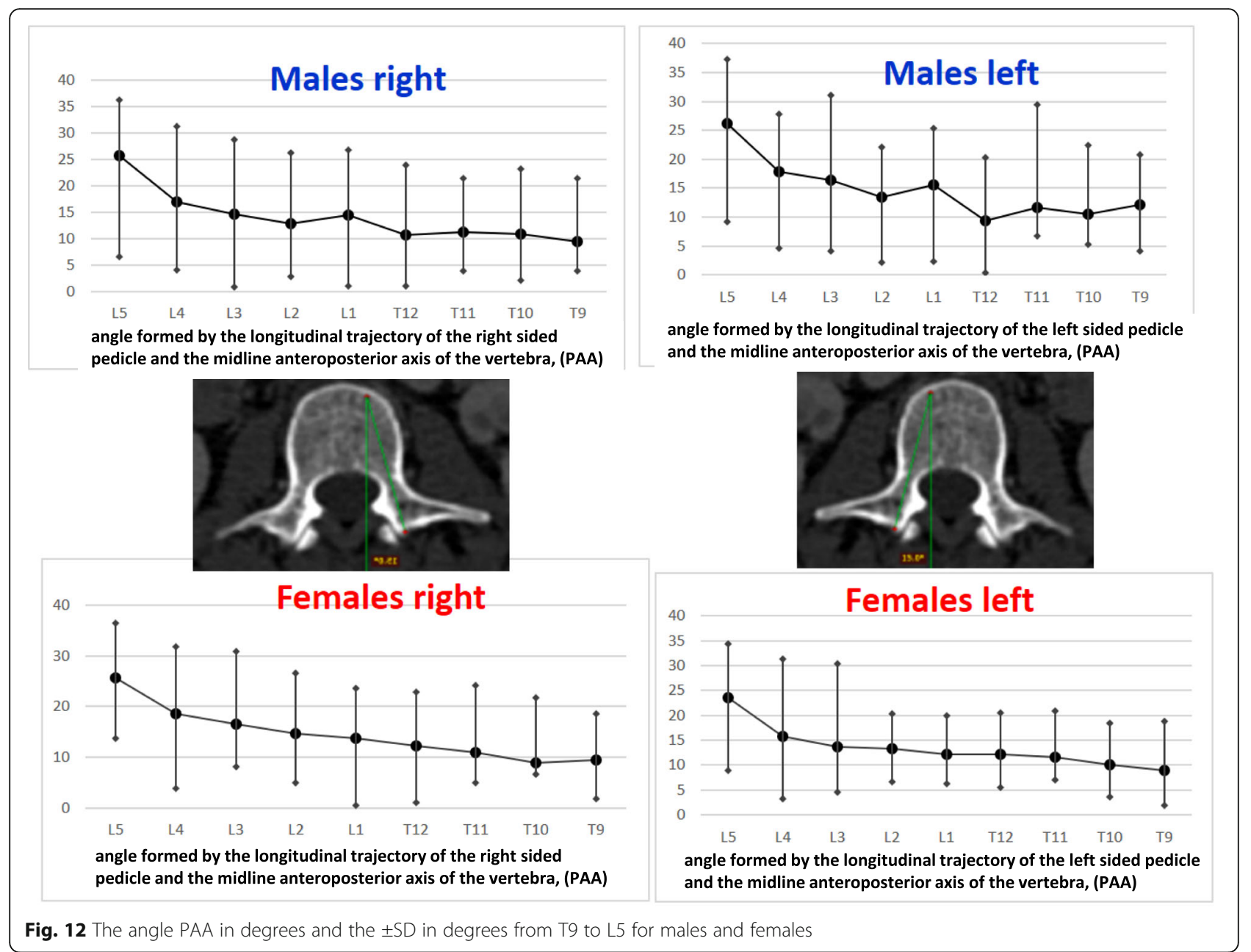

Fig. 12 The angle PAA in degrees and the $\pm S D$ in degrees from T9 to $L 5$ for males and females

0.0-10.5 ${ }^{\circ}$. The longest PTLP in our study was 55.31 $\mathrm{mm}(\mathrm{SD} \pm 4.52 \mathrm{~mm})$ at $\mathrm{L} 4$, at the left pedicle in males and the shortest at $\mathrm{T} 9$, at the right pedicle in females, with a mean of $39.44 \mathrm{~mm}$ (SD $\pm 3 \mathrm{~mm}$ ). However, Zindrick et al. [20] found the longest PTLP (through pedicle axis) at L2 and L3 that was 51.9 $\mathrm{mm}$ (ranges 45.0-58.0 and 42.0-62.0 $\mathrm{mm}$, respectively), Olsewski et al. [21] at L4, and Vaccaro et al. [22] at T12.

As far as the differences between both sexes are concerned, Christodoulou et al. [9] concluded that regarding the internal diameter in the lumbar spine, there was a difference between males and females especially at L3 levels $(p<0.05)$, and almost in all levels regarding the cortex width. In our report, the more pronounced statistically significant difference $(p<0.0001)$ between the two sexes was the PTLP at all vertebral levels from T9 to L5. In this study, the L5 vertebra was found to have the largest AVBH, PAA, and the width of pedicles in both sexes. AVBH was found to be smaller compared to the $\mathrm{PVBH}$ at
T9-L3 vertebral bodies, almost equal at L4 level and greater only at L5 vertebral. This observation may be due to the normal physiological lordosis present in the thoracolumbar region.

Although this study provides important information about the morphometry of vertebrae in the Greek population, it has some limitations. The current findings were obtained from patients visiting a single hospital, and possible differences in the morphometric parameters might exist between Greek people from different geographic regions (i.e., South, West, Central Greece). The male patients were almost four times more than the female ones (79 men and 21 women). Another limitation was the variety of slice thickness at the CT scans (range from $5 \mathrm{~mm}$ to $0.5 \mathrm{~mm}$ ) and at the axial CT scan, which provides only a two-dimensional view of the three-dimensional shape of the pedicles. It is however recommended that the preoperative CT imaging be implemented with thinner slices as possible for a more accurate assessment of the morphometric characteristics of the vertebrae. 


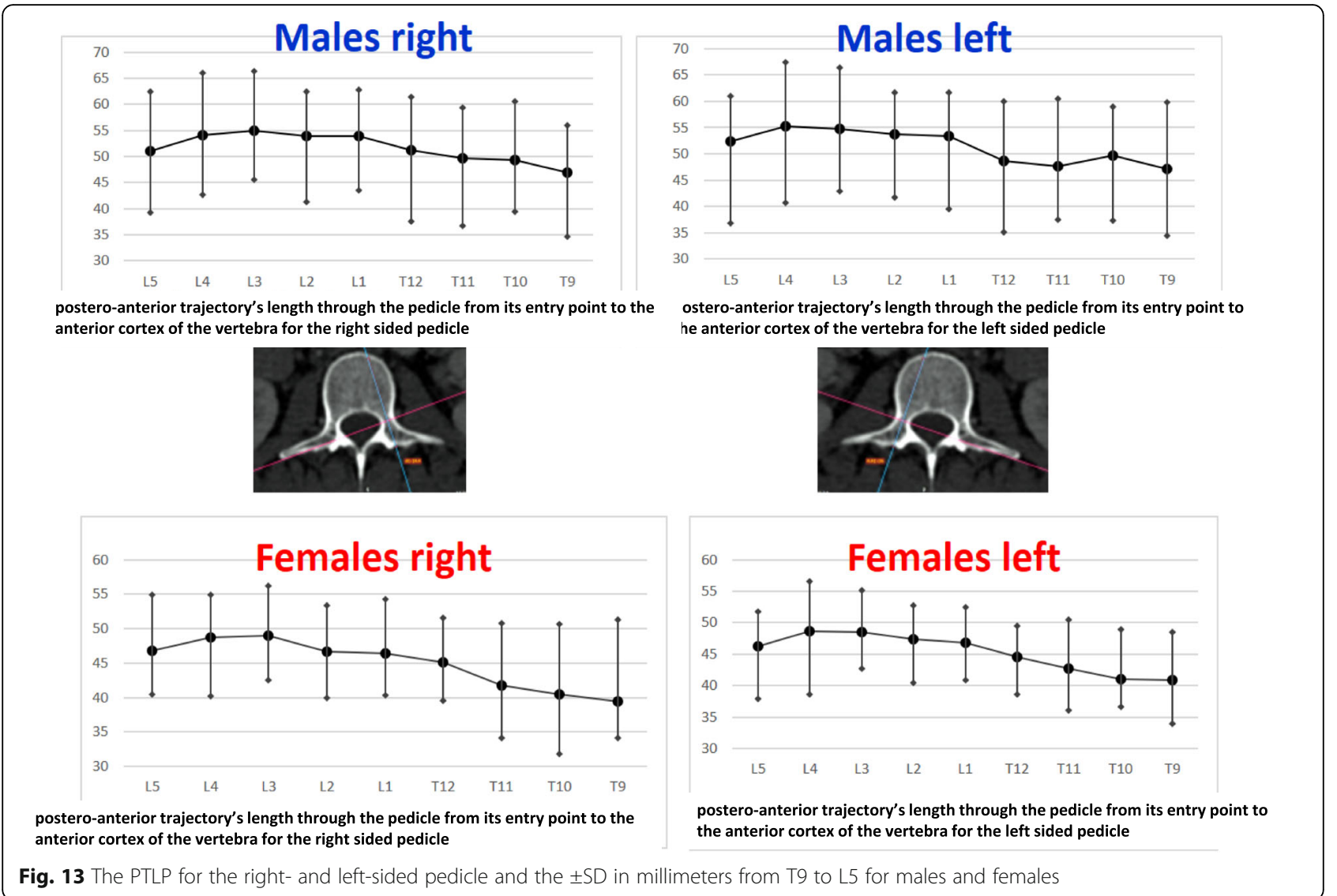

\section{Conclusions}

In conclusion, this study provides a database of morphometric characteristics on thoracolumbar and lumbar vertebrae from T9 to L5 in the Greek population. This database may prove to be of great significance for forthcoming comparative studies. Future studies would also establish the morphometric characteristics of the thoracic regions in the Greek population. It can also serve as a basis in order to detect pathological changes in the spine and furthermore to plan operative interventions.

\section{Abbreviations}

AVBH: Anterior vertebral body height; CT: Computed tomography; L: Lumbar; PAA: Pedicle axis angle; PVBH: Posterior vertebral body height; T: Thoracic

\section{Acknowledgements}

NA

\section{Funding}

No sources of funding were utilized for the study.

\section{Availability of data and materials}

The datasets analyzed during the current study can be requested from the corresponding author by providing a good reason.

\section{Authors' contributions}

TBG performed the study design, developed the study protocol, was involved in the data collection and compilation, described the result analysis, and was involved in drafting the manuscript and searching the literature. OS was involved in drafting the manuscript and searching the literature. SB, GV,
$\mathrm{DL}, \mathrm{MS}, \mathrm{KV}$, and $\mathrm{EV}$ were involved in the data collection. KG was involved in the data collection and performed the statistical analysis. All authors read and approved the final manuscript.

Ethics approval and consent to participate

The study was approved by the Institutional Review Board of our Hospital. Excerpt of the minutes of the Tzaneio General Hospital IRB no: 40, 16/May/2017.

Consent for publication

not applicable.

\section{Competing interests}

All authors declare that they have no competing interests.

\section{Publisher's Note}

Springer Nature remains neutral with regard to jurisdictional claims in published maps and institutional affiliations.

\section{Author details}

'Orthopaedics and Traumatology Department, "Tzaneio" General Hospital of Piraeus, Piraeus, Greece. ${ }^{2}$ National and Kapodistrian University of Athens, First Department of Orthopaedics, "Attikon" University Hospital, Rimini 1, Chaidari, Athens, Greece. Innovative Medical Technologies, Holargos, Athens, Greece.

${ }^{4}$ Queen Mary University of London, London, UK.

Received: 27 March 2018 Accepted: 30 January 2019

Published online: 19 February 2019

\section{References}

1. Schwarzenbach O, Berlemann U, Jost B, Visarius H, Arm E, Langlotz F, Nolte LP, Ozdoba C. Accuracy of computer-assisted pedicle screw placement. An in vivo computed tomography analysis. Spine (Phila Pa 1976). 1997;22(4):452-8. 
2. Merloz P, Tonetti J, Pittet L, Coulomb M, Lavalleé S, Sautot P. Pedicle screw placement using image guided techniques. Clin Orthop Relat Res. 1998;354:39-48.

3. Amiot LP, Lang K, Putzier M, Zippel H, Labelle H. Comparative results between conventional and computer-assisted pedicle screw installation in the thoracic, lumbar, and sacral spine. Spine (Phila Pa 1976). 2000;25(5):606-14.

4. Hart RA, Hansen BL, Shea M, Hsu F, Anderson GJ. Pedicle screw placement in the thoracic spine: a comparison of image-guided and manual techniques in cadavers. Spine (Phila Pa 1976). 2005;30(12):E326-31.

5. Youkilis AS, Quint DJ, McGillicuddy JE, Papadopoulos SM. Stereotactic navigation for placement of pedicle screws in the thoracic spine. Neurosurgery. 2001;48(4):771-8.

6. Ebmeier K, Giest K, Kalff R. Intraoperative computerized tomography for improved accuracy of spinal navigation in pedicle screw placement of the thoracic spine. Acta Neurochir Suppl. 2003;85:105-13.

7. Laine T, Lund T, Ylikoski M, Lohikoski J, Schlenzka D. Accuracy of pedicle screw insertion with and without computer assistance: a randomised controlled clinical study in 100 consecutive patients. Eur Spine J. 2000;9(3):235-40.

8. Cho W, Cho SK. The biomechanics of pedicle screw-based instrumentation. J Bone Joint Surg Br. 2010 Aug;92(8):1061-5.

9. Christodoulou A, Apostolou T, Ploumis A, Terzidis I, Hantzokos I, Pournaras J. Pedicle dimensions of the thoracic and lumbar vertebrae in the Greek population. Clin Anat. 2005; Sep;18(6):404-8.

10. Laine T, Makitalo K, Schlenzka D, Tallroth K, Poussa M, Alho A. Accuracy of pedicle screw insertion: a prospective $\mathrm{CT}$ study in 30 low back patients. Eur Spine J. 1997:6(6):402-5.

11. Goel VK, Gilbertson LG. Basic science and spinal instrumentation. Clin Orthop Relat Res. 1997;335:10-31.

12. Varghese V, Kumar GS, Krishnan V. Effect of various factors on pull out strength of pedicle screw in normal and osteoporotic cancellous bone models. Med Eng Phys. 2017;40:28-38.

13. Weinstein JN, Spratt KF, Spengler D, Brick C. Spinal pedicle fixation: reality and validity of roentgenogram-based assessment and surgical factors on successful screw placement. Spine. 1998;13:1012-6.

14. Kosmopoulos V, Schizas C. Pedicle screw placement accuracy: a metaanalysis. Spine (Phila Pa 1976). 2007;32(3):E111-20.

15. Kretzer RM, Chaput C, Sciubba DM, et al. A computed tomography-based morphometric study of thoracic pedicle anatomy in a random United States trauma population. J Neurosurg Spine. 2011;1(4):235-43.

16. Biscevic M, Biscevic S, Ljuca F, et al. Clinical and radiological morphometry of posterior parts of thoracic and lumbar vertebras. Coll Antropol. 2012; 36(4):1313-7.

17. Acharya S, Dorje T, Srivastva A. Lower dorsal and lumbar pedicle morphometry in Indian population. A study of four hundred fifty vertebrae. Spine. 2010;35:E378-84.

18. Avuthu S, Salian PRV, Kotian P, Shetty BSK. Computed tomographic morphometry of thoracic and lumbar pedicles in south Indian population. Asian J Pharm Health Sci. 2014;4(2):996-1000.

19. Liau KM, Yusof Ml, Abdullah MS, Abdullah S, Yusof AH. Computed tomographic morphometry of thoracic pedicles: safety margin of transpedicular screw fixation in Malaysian Malay population. Spine. 2006;31:545-50.

20. Zindrick MR, Wiltse LL, Doormik A, Widell EH, Knight GW, Patwardhan SG, Thomas JC. Analysis of the morphometric characteristics of the thoracic and lumbar pedicles. Spine. 1987;12:160-5.

21. Olsewski JN, Simmons EH, Kallen FC, Mendel FC, Severin CM, Berens DL. Morphometry of the lumbar spine: anatomical perspectives related to transpedicular fixation. J Bone Joint Surg Am. 1990;72:541-9.

22. Vaccaro AR, Rizzolo SJ, Allardyce TJ, Ramsey M, Salvo J, Balderston RA, Cotler $J M$. Placement of pedicle screws in the thoracic spine: morphometric analysis of the thoracic vertebrae. J Bone Joint Surg Am. 1995;77:1193-11.

Ready to submit your research? Choose BMC and benefit from:

- fast, convenient online submission

- thorough peer review by experienced researchers in your field

- rapid publication on acceptance

- support for research data, including large and complex data types

- gold Open Access which fosters wider collaboration and increased citations

- maximum visibility for your research: over $100 \mathrm{M}$ website views per year

At BMC, research is always in progress.

Learn more biomedcentral.com/submissions 